\title{
REVISORES TÉCNICOS
}

$\begin{array}{ll}\text { Nombre } & \text { Institución } \\ \text { Allan González Herrera } & \text { UNA } \\ \text { Bernardo Mora Brenes } & \text { Consultor } \\ \text { Beatriz Molina Bermúdez } & \text { MAG } \\ \text { Beatriz Sandoval Carvajal } & \text { INTA } \\ \text { Carlos Luis Loría Quirós } & \text { UCR } \\ \text { Cristina Vargas Chacón } & \text { INTA } \\ \text { Francisco Álvarez Bonilla } & \text { MAG } \\ \text { Jorge Mora Bolaños } & \text { INTA } \\ \text { Juan Mora Montero } & \text { INTA } \\ \text { Juan R. Mora Camacho } & \text { UNA } \\ \text { Laura Ramírez Cartín } & \text { INTA } \\ \text { Luis Alpízar Oses } & \text { INTA } \\ \text { Luis D. Monge Montero } & \text { Consultor } \\ \text { María Mesén Villalobos } & \text { INTA } \\ \text { Mauricio Chacón Navarro } & \text { MAG } \\ \text { Nevio Bonilla Morales } & \text { INTA } \\ \text { Ricardo Guillén Montero } & \text { MAG } \\ \text { Ricardo Piedra Naranjo } & \text { INTA } \\ \text { Rodolfo Araya Villalobos } & \text { Consultor } \\ \text { Yannery Gómez Bonilla } & \text { INTA } \\ \text { Sayra Munguía Ulloa } & \text { Consultora } \\ \text { Sergio Abarca Monge } & \text { INTA } \\ \text { William Villalobos Muller } & \text { UNA } \\ \text { William Sánchez Ledezma } & \text { INTA }\end{array}$

\section{REVISTAALCANCES TECNOLÓGICOS En línea www.platicar.go.cr}


La semilla del híbrido Pococí se encuentra disponible en las estaciones experimentales Los Diamantes del INTA, ubicada en Guápiles y en la Fabio Baudrit Moreno de la UCR, ubicada en la Garita de Alajuela. Durante el 2012 ambas estaciones abastecieron de semilla a no menos de 300 productores para un total de 750 ha sembradas del híbrido en todo el país.

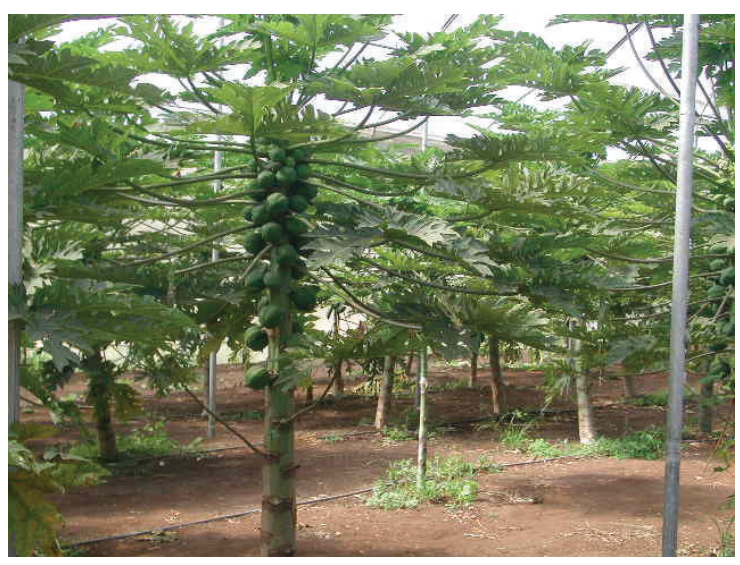

Figura 3. Producción de semilla en invernadero. EEFBM. Alajuela, Costa Rica. 2011.

En la actualidad el proceso de mejora continúa buscando nuevas variedades con buenas características productivas y gustativas que satisfagan a los usuarios del país y del exterior.

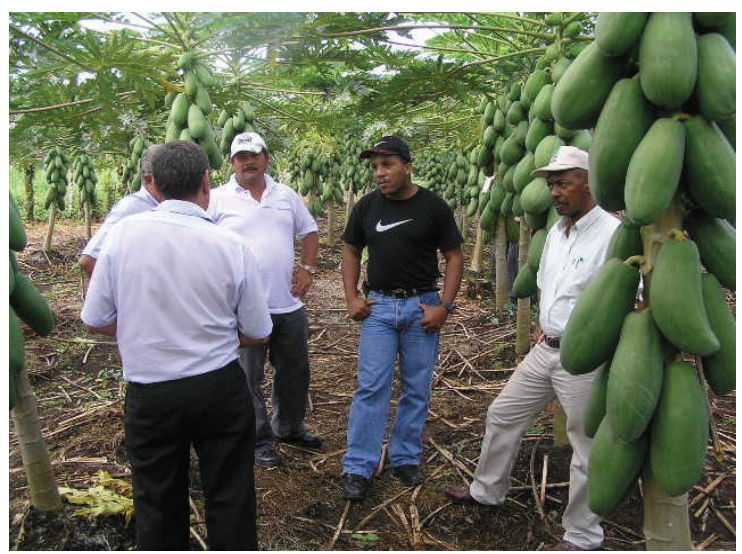

Figura 4. Día demostrativo de un nuevo material de papaya con técnicos y productores. Guácimo, Costa Rica. 2011.
La tecnología generada en el proyecto se transfiere a los productores a través de las respectivas acciones institucionales y también en conjunto con el equipo técnico del Programa de Investigación y Transferencia de Tecnología (PITTA) papaya.

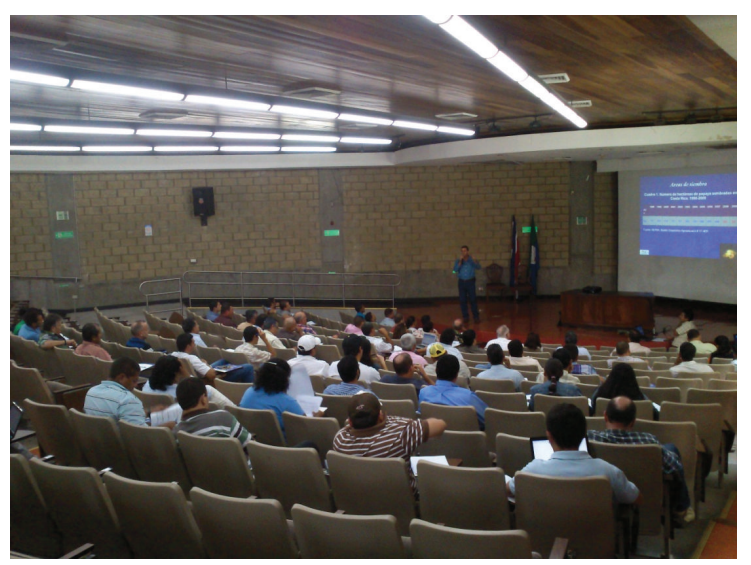

Figura 5. Curso nacional sobre manejo de la papaya. PITTA papaya. San José, Costa Rica. 2011.

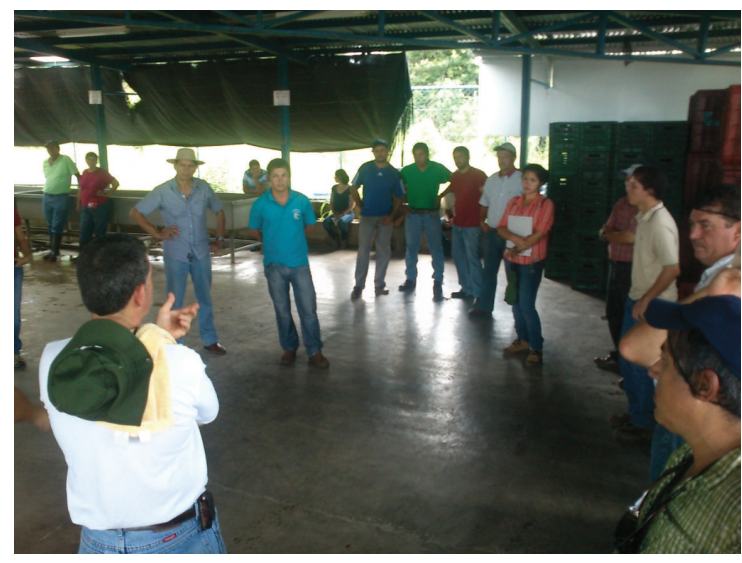

Figura 6. Día de campo en la planta empacadora del Centro Agrícola de Guácimo. PITTA papaya. Limón, Costa Rica. 2011. 


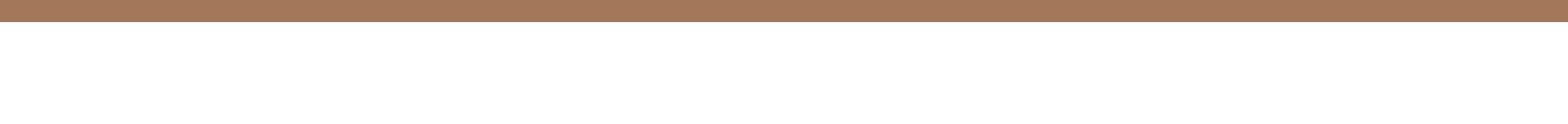

